\title{
Dr. Robert G. Heath: a controversial figure in the history of deep brain stimulation
}

\author{
Christen M. O'Neal, BS, Cordell M. Baker, BS, Chad A. Glenn, MD, Andrew K. Conner, MD, and \\ Michael E. Sughrue, MD
}

Department of Neurosurgery, University of Oklahoma Health Sciences Center, Oklahoma City, Oklahoma

\begin{abstract}
The history of psychosurgery is filled with tales of researchers pushing the boundaries of science and ethics. These stories often create a dark historical framework for some of the most important medical and surgical advancements. Dr. Robert G. Heath, a board-certified neurologist, psychiatrist, and psychoanalyst, holds a debated position within this framework and is most notably remembered for his research on schizophrenia. Dr. Heath was one of the first physicians to implant electrodes in deep cortical structures as a psychosurgical intervention. He used electrical stimulation in an attempt to cure patients with schizophrenia and as a method of conversion therapy in a homosexual man. This research was highly controversial, even prior to the implementation of current ethics standards for clinical research and often goes unmentioned within the historical narrative of deep brain stimulation (DBS). While distinction between the modern practice of DBS and its controversial origins is necessary, it is important to examine Dr. Heath's work as it allows for reflection on current neurosurgical practices and questioning the ethical implication of these advancements.
\end{abstract}

https://thejns.org/doi/abs/10.3171/2017.6.FOCUS17252

KEY WORDS deep brain stimulation; ethics; functional; lobotomy; psychosurgery; history; Robert G. Heath

In order to modify man's behavior at the social level, it is necessary to establish more effective moral codes... If one day a common moral code evolved, and biologic methods applied so as to imprint firmly the memories of that code, it might be possible for man to live in harmony with this fellow man, as well as with other species.

$$
\text { - Robert G. Heath, } 1996^{12}
$$

It seems to me that it is the physician's responsibility to ascertain that new techniques are used constructively to alleviate, whenever possible, personal handicaps and discomforts and to increase man's ability to live with his fellow man.

$$
\text { - Robert G. Heath, } 1973^{40}
$$

\section{Early Life and Education}

Robert Galbraith Heath was born in Pittsburgh, Pennsylvania, on May 9, 1915. ${ }^{9}$ He was encouraged to study medicine from a young age. As Heath recounted in an interview toward the end of his career, his father, a general practitioner, "pushed" Heath into medicine with the hope that he would "follow in his footsteps."15 In 1938, Heath completed his medical education at the University of Pittsburgh (Fig. 1), the same institution he attended for his undergraduate studies. ${ }^{9}$ After medical school and a yearlong internship at Mercy Hospital in Pittsburgh, Heath was accepted as an internal medicine resident at McGill University. However, the year he was to start residency his father died, and Heath took over his father's general practice. ${ }^{15}$ It was during this time that Heath decided to pursue a career in neurology. He made this decision with the guidance of his soon-to-be father-in-law who was a faculty neurologist at the University of Pittsburgh. Heath went on to train at the prestigious Neurological Institute in New York, after which he was appointed as a fellow in psychiatry at Penn-

ABBREVIATIONS CIA = Central Intelligence Agency; DBS = deep brain stimulation; EEG = electroencephalography; LSD = lysergic acid diethylamide 


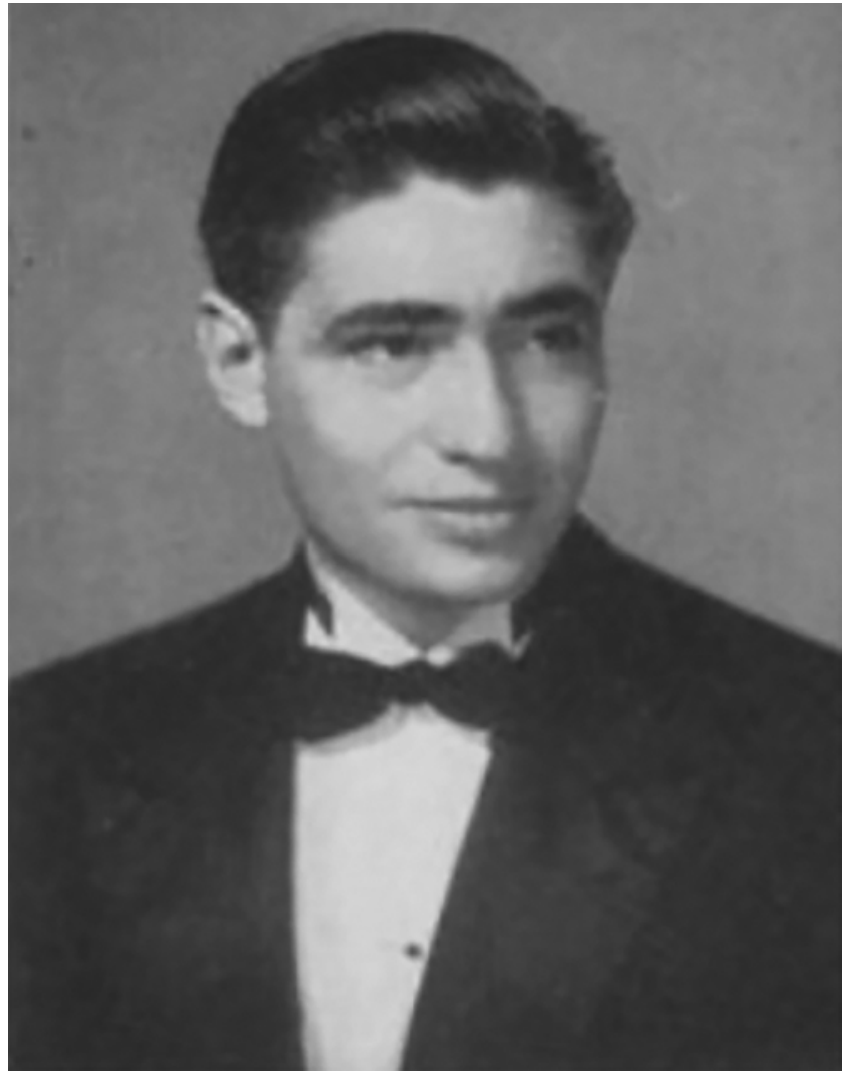

FIG. 1. Robert G. Heath as a medical student at the University of Pittsburgh. Used with permission from the University Archives at The University of Pittsburgh.

sylvania Hospital in Philadelphia. ${ }^{39}$ World War II interrupted Heath's training, and he was drafted to the United States Navy. ${ }^{39}$

\section{Military Service and the Columbia-Greystone Project}

Despite being a board-certified neurologist and never finishing his psychiatric training, the military drafted Heath as chief psychiatrist at the United States Marine Hospital in New York. ${ }^{9}$ According to Heath, this kind of career shift in the military was typical for neurologists. There was a higher demand for psychiatrists, and "the medical hierarchy at that point considered anyone who treated nerves to be also able to treat nervous people." 15 With only 2 months of formal training, Heath practiced psychiatry for 2 years. ${ }^{9,39}$ During this time, he started a family and began what would become a long and prolific research career. In 1944, Heath published a review of his clinical experiences using pharmacological agents to treat soldiers with "traumatic war neuroses." 25 This was one of his first articles to be published, and it incorporated many ideas that he would revisit throughout his later years in research. Heath's research methods combined a biological and psychoanalytical approach to studying psychiatric disorders and placed an emphasis on the emotional pathways involved. ${ }^{11}$

Upon returning from the war, Heath continued his studies at Columbia's College of Physicians and Surgeons with a fellowship at the Psychoanalytical Clinic under Dr. Sandor Rado. ${ }^{8,9,15,32}$ Dr. Rado's stance on psychoanalysis influenced Heath to incorporate a multidisciplinary approach in his later research. ${ }^{9}$ These beliefs placed an emphasis on understanding the neurophysiological basis of psychiatric diseases, a concept championed by Sigmund Freud ${ }^{9}$ and an underlying principle of Heath and Rado's research at Columbia. ${ }^{4,32}$

In 1948, Heath became the senior psychiatrist on a research initiative known as the Columbia-Greystone Project., ${ }^{42}$ The primary goal of this project was to find a safer and more effective neurosurgical alternative to lobotomy. ${ }^{4,31}$ The procedure that was developed became known as topectomy and involved excising smaller and more superficial portions from the frontal lobes. ${ }^{29}$ According to their research, the indications for topectomy were essentially the same as the indications for a prefrontal lobotomy, with the exception that the less aggressive tissue removal of the procedure was not suitable for rendering a violent psychotic patient into a "tractable" one. ${ }^{31}$ The researchers argued in favor of topectomy as a safer alternative and claimed that the procedure signified a more quantitative approach for intervention in patients with schizophrenia, depression, and obsessive-compulsive disorder. ${ }^{31}$ Heath was skeptical of these conclusions and felt that, much like lobotomy, topectomy only reduced the appearance of symptoms by blunting emotions and causing an overall flattening of the patient's affect. ${ }^{9}$ Heath sought to explore deeper cortical structures that he believed were responsible for emotion and directly linked with psychiatric disease. ${ }^{915}$ However, the team disagreed with Heath, and he left his position at Columbia in pursuit of research opportunities that would allow him to investigate his hypotheses. ${ }^{13}$ In 1949 Heath accepted a position at Tulane University in Louisiana, where he was promised complete academic freedom. ${ }^{28}$

\section{Tulane University, Schizophrenia, and Patient B-19}

Tulane offered Heath a position as the chairman of a new, multidisciplinary department in neurology and psychiatry. ${ }^{9,29,33}$ At the time, committees did not appoint or recruit new faculty members. Instead, it was the responsibility of the Dean of Tulane University's School of Medicine, Dr. Maxwell Lapham, who "was determined to build academic medicine at Tulane." ${ }^{15}$ Dr. Lapham was interested in Tulane being recognized as a prestigious university, which could be done with the publicity from a noteworthy research endeavor. ${ }^{9}$ Heath, as a new researcher with bold ideas in the rapidly expanding fields of psychiatry and neurology, immediately attracted the attention of Lapham, who saw great potential in Heath's research goals.

Heath's acceptance of the position marked the beginning of his research into the role of deep cortical brain regions and the biological basis of schizophrenia. ${ }^{11,17,24} \mathrm{His}$ initial work on the Columbia-Greystone Project and the training he received from Dr. Rado greatly impacted his research at Tulane and was the basis for his decision to selectively ablate Brodmann areas 9 and $10 .{ }^{14}$ These re- 
gions, Heath argued, were critical in pain and emotional responses. ${ }^{14,31}$ To spare the patient's emotions but still combat the negative emotional response seen in schizophrenia, Heath targeted areas associated with the pleasure drive as described by Rado. ${ }^{12}$ Heath would go on to define the connections between Brodmann areas 9 and 10 and the septal area. This region would become Heath's motivation for pursuing electrical stimulation in deep cortical structures..$^{14}$

Much of Heath's initial research at Tulane was documented in his monograph from 1954, Studies in Schizophrenia. ${ }^{5}$ In this work, Heath detailed his experimental findings from 25 cases of electrical brain stimulation, which were performed primarily for the "therapeutic" benefit of patients diagnosed with schizophrenia. ${ }^{5}$ Inserting electrodes in the brain in the early 1950s presented a number of difficulties. Stereotactic technique was relatively new at this time, and, as such, the first 19 patients underwent "open" electrode placement. ${ }^{5}$ Neurosurgeons affiliated with Tulane performed the open procedures at Charity Hospital of Louisiana in New Orleans. ${ }^{14}$ This method consisted of making an incision through the cortex to the anterior horn of the lateral ventricle, allowing visualization of landmarks for electrode placement. The length of time for electrode placement varied by patient, with some receiving electrical stimulation immediately and then removal for closure, and others having electrodes left in place. A diagram illustrating Heath's laboratory that was originally published in Studies in Schizophrenia is shown in Fig. 2. The sketch depicts 2 rooms: one room houses the patient with implanted cerebral electrodes and the other room houses the electrical stimulation and recording equipment.

Heath used a variety of stimulation parameters, although there were 5 general methods he cited from his initial studies with animals. These parameters differed based on the type of electrodes used, which may in part explain the experimental variations. ${ }^{14}$ The values reported for peak current ranged from 0.5 to $40 \mathrm{~mA}$, peak voltage ranged from 1 to $36 \mathrm{~V}$, and duration of stimulation was reported from 4 to 40 minutes. There are further variations in the number of stimulations each patient received; several patients received 1 or 2 stimulations, although the majority received 4 or more. Patient 12 received the highest number of stimulations, amounting to 28 in total. Some of the initial experiments lack values for the peak voltage or report a question mark for peak current, while other patients are missing data for the duration of stimulation. The discrepancy in data are illustrated in the case of Patient 3 in which Heath states, "as a result of a shorted electrode... [the patient] probably received no current." 14 Due to the inconsistency in reported data on these cases, it is difficult to ascertain any definite parameters used in Heath's studies.

Figure 3 depicts electrodes implanted in a patient who underwent deep brain stimulation (DBS) therapy for schizophrenia. This plug-in arrangement was a modified version of Heath's original lead system and consisted of a plastic headpiece fitted with a special connector. Heath's laboratory at Charity Hospital constructed the electrodes before they were implanted in patients. The majority of

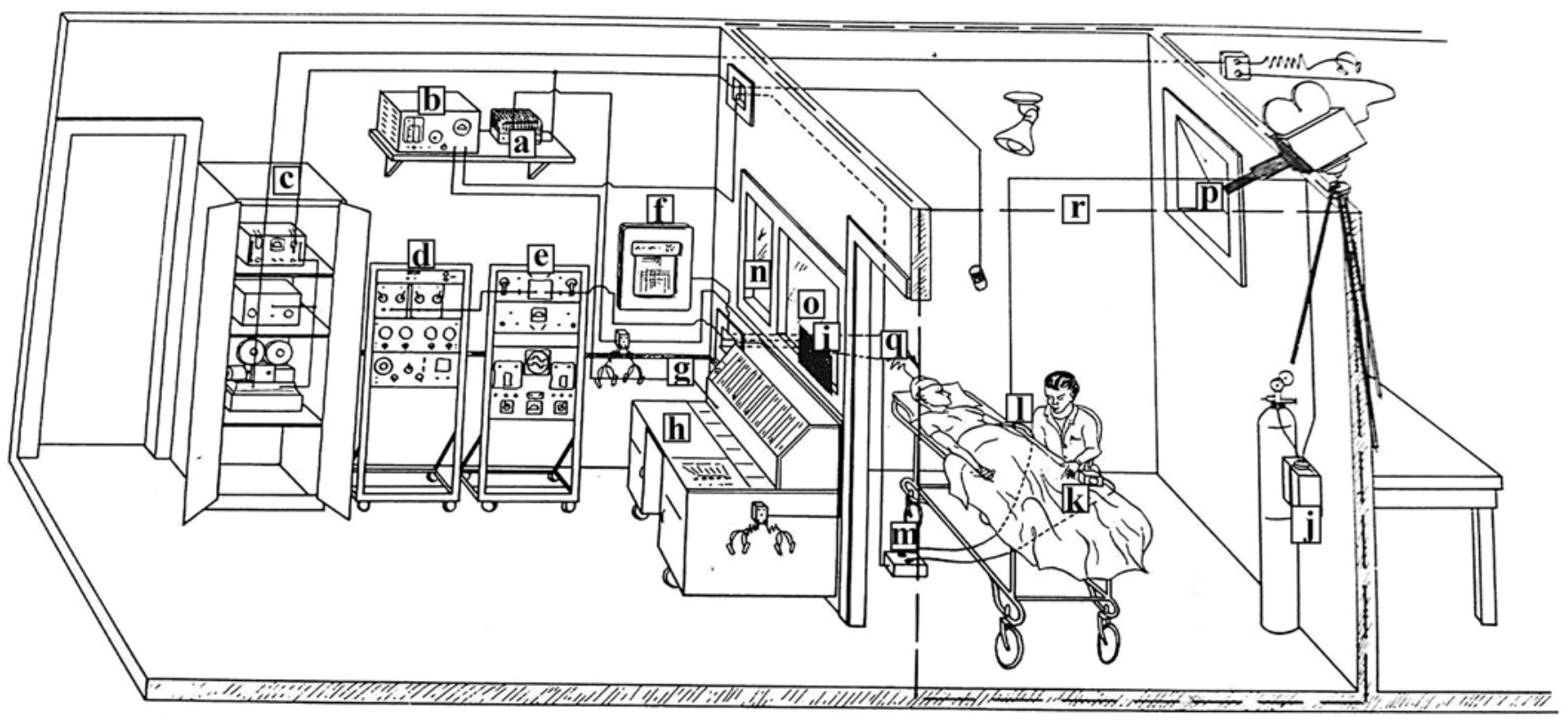

FIG. 2. Diagram of Heath's laboratory. The image illustrates a cross-section of the patient and instrument room. The labels in the illustration depict the following: a, audio amplifier fed by microphone in the shielded room (the output is connected to headphones for personnel in the instrument room); b, electronic equipment for recording intraarterial blood pressure on EEG; $c$, motion picture sound-recording equipment; $d$, electrical stimulating equipment; e, stimulus monitor and calibrating equipment; $f$, skin temperature recorder; g, electrical ground bus; h, electroencephalograph; i, stimulate-record panel (in shielded room); j, saline reservoir and pressure tank with regulator; $\mathrm{k}$, utility blood pressure indicating meter; l, blood pressure transducer; $\mathrm{m}$, blood pressure junction box; $n$ and $o$, semitransparent mirrors; $p$, motion picture camera port; $q$, thermocouples to 8 points on the body; r, electrostatic shield. Reprinted from Studies in Schizophrenia with permission of The Commonwealth Fund. 


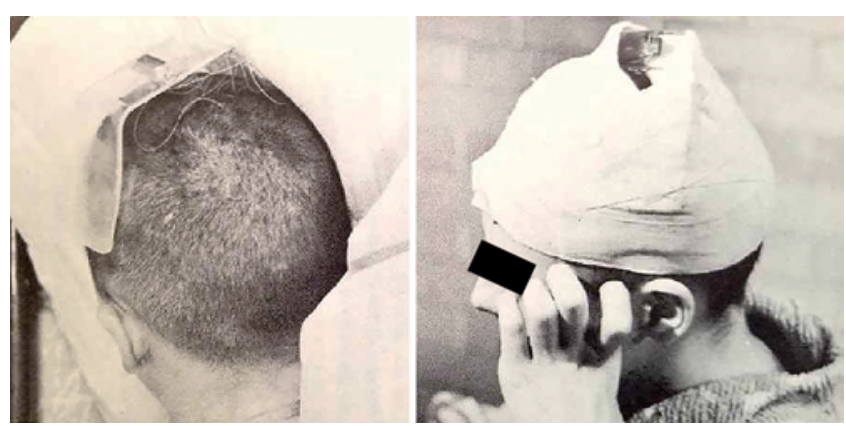

FIG. 3. A patient of Heath's who underwent DBS therapy for schizophrenia. This plug-in arrangement was a modified version of their initial lead system and consisted of a plastic headpiece fitted with a special connector. Left: Photograph showing the plastic headpiece with an electrode connecter. Wires can be seen going from the connecter lead pins to the scalp. Right: The plastic headpiece is wrapped with dressing, leaving only the connector exposed. Reprinted (left) and modified (right; bar over patient's eyes) from Studies in Schizophrenia with permission of The Commonwealth Fund.

electrodes consisted of a lead wire surrounded by a polyethylene sleeve with an exposed noninsulated tip. Unipolar as well as bipolar stimulation was used. Similar to Heath's stimulation parameters, he used a variety of electrode arrangements in a single study. ${ }^{14}$

Without the advents of modern technologies, electrode placement was highly inaccurate; the "open technique" caused brain damage, and patients were prone to postoperative infection..$^{5,6,14,18}$ It was not until the later years of Heath's work that he would implement stereotactic techniques that would resemble the methods used for modern electrode placement. Figure 4 shows the stereotactic head frame used at Tulane by Heath, and, for comparison, a modern head frame is shown. While Heath credits neurosurgeons affiliated with Tulane for performing the open operations, it is less clear who performed the stereotactic procedures. In a chapter discussing stereotactic implantation, a Tulane-affiliated neurosurgeon is cited as a contributing author, suggesting that similar to open procedures, neurosurgeons were likely involved in electrode placement. ${ }^{14}$

While the first part of the monograph details the theory, methods, and results of the 25 case reports, the final portion is a compilation of written responses from guests attending a 1952 symposium at Tulane University, many of which are critical of the scientific basis of Heath's research and the flaws in his methodological approach.${ }^{14}$ One guest had spoken with Dr. Rado about Heath's work and remarked that although Rado was proud of Heath's accomplishments, he was disappointed by Heath's experimental methods and ultimately disagreed with the conclusions of his research. ${ }^{9,14}$ Dr. Fred A. Mettler, a neuroanatomist and former instructor of Heath's, was also critical..$^{14}$ Mettler had also worked on the Columbia-Greystone Project, and Heath had referenced several of Mettler's papers to support his experimental procedures of stimulating the septal area. ${ }^{14,26,27}$ Mettler was disappointed that Heath so liberally cited his work and suggested that much of the data Heath referenced was taken to fit the needs of his experiments. ${ }^{14}$ Mettler stated, "It is somewhat disturbing to find, in some instances where, as in Case 25, postmortem material is available, that the authors' morphological terminology does not entirely agree with accepted anatomic usage." 14 In other words, Heath's misidentification of postmortem anatomy suggested that he might have been misplacing electrodes in his patients. The strong, negative reactions from the scientific community did not go unnoticed by Heath. Although he was reluctant to invite further speculation, he continued to publish findings from his experiments with little alteration in his methods or explanation of the scientific basis for the experiments. ${ }^{5,9}$

The therapeutic results from Heath's trials did not always match his ambitions. In Studies in Schizophrenia, Heath claimed that 5 of the 20 initial patients showed "marked improvement" and 8 of 20 "significant improvement."14 However, these improvements may have been the result of patients receiving extra attention; Heath himself acknowledged that the long-term benefits of the intervention could not be evaluated. Eventually, Heath stopped these studies, coming to the realization that "the lasting beneficial effects in the patient group...had not been significant." " Regardless of whether Heath's research resulted in psychiatric improvement, it is difficult to ignore the postoperative complications that ensued from the study. Of 20 patients in the initial group, 2 developed brain abscesses and died, 3 had seizures in the immediate postoperative period, and another 2 patients had seizures that continued after 6 months. There are also multiple accounts of the stimulations causing adverse reactions. For instance, after stimulation one patient "expressed great fear, and at one point it took four or five people to restrain her."'14 Despite these complications, Heath continued to defend his work and decades later would state, "The reality was lost that we were treating patients with sick minds who could be helped only by redirecting their minds towards health." 12

In 1955, just a year after publishing his first monograph, Heath and colleagues published a separate case report entitled "Stimulation of the amygdaloid nucleus in a schizophrenic patient." ${ }^{24}$ The report describes his findings from an experimental procedure in which Heath alternated between 2 intensities of deep cortical stimulation in the amygdala. Heath was surprised that repeated stimulation during subsequent treatments in the same patient yielded different responses despite radiography confirming consistent electrode placement. Secondary stimulation evoked a fear response rather than the initially observed rage with identical stimulation parameters. ${ }^{24}$ Heath's report placed an emphasis on defending his research rather than exclusively describing a therapeutic technique. It is clear that Heath was aware of the criticism he was likely to receive for this publication and therefore felt it was necessary to point out the importance of conducting research with human participants. He wrote, "Several authors discuss apparent alterations in the emotional responses of animals with stimulation and ablation of the amygdaloid nucleus. In the animal studies it is difficult to evaluate accurately the meaning of the observed phenomena since the animal is unable to report." 24

In the same year, Heath began investigating the pathological basis for schizophrenia. ${ }^{11,22,36}$ Much of the criticism from Heath's peers was based on his transition from 

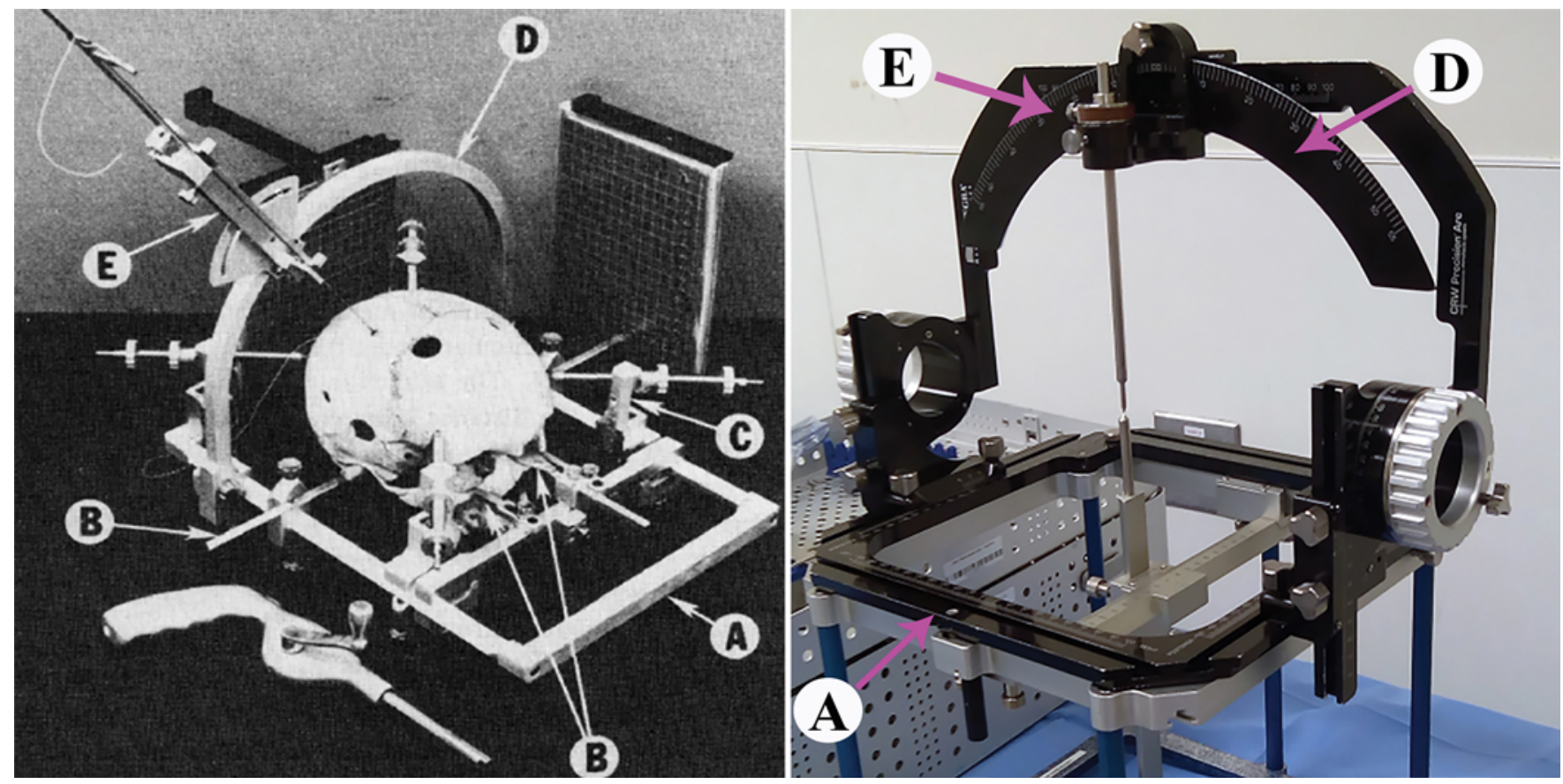

FIG. 4. Stereotactic frame for placement of electrodes in DBS. Left: Head frame used at Tulane University by Robert G. Heath, which has a close resemblance to the image on the right. Reprinted with permission from IEEE Transactions on Biomedical Engineering. Right: Integra CRW Precision Arc modern frame used for electrode placement. The labels in the illustration depict the following: $A$, rectangular base; $B$, preliminary bone fixation assembly; $C$, final posterior bone fixation assembly; $D$, semicircular carrier frame; E, electrode carrier assembly.

animal experimentation to human trials. ${ }^{15}$ Heath injected 30 to 40 "human volunteers" with a serum he had extracted from patients with schizophrenia. ${ }^{15}$ Heath claimed the serum contained a new immunoglobulin that he had discovered called taraxein and that it was the molecular basis of schizophrenia. ${ }^{21}$ Heath reported that the "human volunteers" contracted symptoms associated with schizophrenia for about an hour after injection with the serum. Several other scientists attempted to replicate the findings but all attempts were unsuccessful. ${ }^{38}$ When asked why his work on schizophrenia and taraxein was met with so many negative reactions, Heath responded that he received significant pushback from the psychiatric community, which was far more interested in a psychoanalytical approach than a biological one. For this reason, Heath claimed that other scientists were already biased of his work and therefore quick to discredit his findings. A contemporary of Heath, Elliot Valenstein, now professor emeritus of psychology and neuroscience at the University of Michigan, commented on Heath's methods,

My criticism of Heath was really that he didn't seem to know how to test his own conclusions for verification. He was always interested in results that were spectacular-like finding some protein in the brain that would evoke schizophrenia. He'd published papers of that sort but never really looked for alternative explanations, never tested the reliability of his findings, was very willing to rapidly publicize his findings, so that he was quite unreliable. ${ }^{41}$

In the following years, Heath's studies on brain stimulation expanded to electrical recording of cerebral activity. A number of studies explored the effects of drugs such as lysergic acid diethylamide (LSD) and mescaline on the human central nervous system utilizing electrode recordings..$^{19,20,30}$ Authors have speculated that these studies were funded by the Central Intelligence Agency (CIA) under the project entitled MKUltra, although Heath denied any such involvement. 9,16,19,29,36 However, Heath did admit to being approached by a CIA official to conduct government research but claimed that he was not interested as he was more concerned with caring for his patients. ${ }^{5,9}$ Despite his public denial, a scandal arose surrounding Heath's, and therefore Tulane's, suspected involvement in government research. Students at Tulane University and the general public were outraged that the government might have been guiding psychiatric research toward what they believed to be an attempt at "mind-control."12,29,36 The truth about these experiments would be disclosed in 1977 under the Freedom of Information Act. Tulane had indeed signed an army "facility security clearance" for the Department of Psychiatry and Neurology in 1956. Whether the LSD and mescaline trials were government sponsored is still debated, but the few surviving military records do refer to Heath testing a drug in several monkeys and an inmate who was also being tested in the Soviet Union for "mind controlling applications." ${ }^{29}$ Heath's collusion with the CIA, as well as negative publicity in the 1970s from nonscientific publications criticizing Heath's work, manifested in poor public relations. These publications included a New Orleans newspaper article, "The mysterious experiments of Dr. Robert Heath in which we wonder who is crazy and who is sane," and the 1978 book The Mind Manipulators, which also makes mention of Heath's studies. ${ }^{34,36}$ 
By the late 1960s, Heath had significantly decreased the number of patients he was treating with brain electrode stimulation. ${ }^{5}$ However, in 1972, Heath published findings from his highly controversial and likely most recognizable work, the experimental treatment of patient B-19 with DBS. ${ }^{11,13}$ There are conflicting accounts of the events preceding the treatment, namely the patient's motivation for seeking treatment and Heath's reason for agreeing. According to Heath, patient B-19 had been hospitalized on multiple occasions after being diagnosed with "depressive reaction." Subsequent diagnoses for patient B-19 included "personality disorder with homosexual behavior and drug experimentation" and "temporal lobe dysfunction."13 Heath reported that the patient requested treatment for homosexuality, although other accounts suggest that patient B-19's treatment was court ordered following drug charges. ${ }^{36}$

Regardless of the events leading up to patient B-19's treatment, Heath would attempt to use DBS as a method for homosexual conversion therapy. As a secondary goal, Heath sought to obtain electroencephalography (EEG) recordings during orgasm. The electrodes were placed in various locations including septal, hippocampal, amygdaloid, hypothalamic, caudate, and cerebellar regions. ${ }^{13} \mathrm{Af}-$ ter electrode placement, researchers provided patient B-19 with a button to push that would send a current through the electrodes to his "pleasure site." 13,28 As Heath and his colleagues recorded the patient's cerebral activity, patient B-19 was instructed to push the button repeatedly while watching heterosexual erotic films and masturbating until orgasm. ${ }^{11}$ According to Heath, the goal of this exercise was that the patient would become heterosexual after developing an association between women and the electrical stimulation of his "pleasure site." In the final stage of the patient's treatment, Heath and his colleagues received state court approval to hire a 21-year-old female prostitute to perform sexual acts with patient B-19, aiming to finalize his newfound interest in heterosexuality. The sexual acts were performed with the electrodes in place while the patient's EEG recordings were monitored from another room. ${ }^{5}$ The long-term behavior of patient B-19 is another point of contention; while Heath claimed that the patient had a full recovery and engaged exclusively in heterosexual activities, other sources argued that the patient continued to have homosexual relationships. ${ }^{5,36}$

Criticisms of Heath's methods were not limited to his colleagues in the psychiatric and neurology community. There are documented accounts of neurosurgeons vehemently criticizing Heath's practices. Lauri Laitinen, a Swedish neurosurgeon, responded to a paper published by Heath in 1972:

In these two patients electrodes and cannulas implanted into most structures of the brain numbered no less than 19 and 29 , respectively, and little attempt was made to document why this was important for the patients' treatment. There is no doubt that in this study all standards of ethics had been ignored. The ethical responsibility of the editors who accept reports of this kind for publication should also be discussed. ${ }^{10}$

Another neurosurgeon, Dr. James Campbell from Columbia University College of Physicians and Surgeons was also skeptical of Heath's work. Similar to Mettler, Campbell thought Heath misidentified brain anatomy and lacked objectivity in presenting data. ${ }^{14}$ In fact, some authors have argued that neurosurgeons unjustly burden the majority of blame in early psychosurgical practices and that oftentimes, it was nonneurosurgeons who were the primary advocates pushing for these procedures. ${ }^{10,11}$

Only a year after his study on patient B-19, Heath's ethical conduct was questioned before a subcommittee in the United States Senate, led by Senator Ted Kennedy. ${ }^{40}$ The subcommittee was investigating the ethical practices implemented by laboratories performing human research. In his statement, Heath defended his studies stating, "We insist that all patients, as well as responsible family members, are thoroughly informed of the nature of the procedures and of every possible undesirable, complication before forms are signed and the procedures are undertaken." ${ }^{40}$ Not all modern critics seem to agree with Heath's definition of informed consent, and several skeptics reference a New Orleans newspaper article that allegedly contained a copy of the consent form. ${ }^{5,9}$ These critics question the extent to which Heath actually informed his patients of the procedures they were consenting to, claiming he failed to discuss the risk of seizure or coma, which occurred in several patients. ${ }^{5,9,14}$

\section{Later Years, Death, and Reception}

In 1980, Heath retired from his position as Chairman of Tulane's Department of Psychiatry and Neurology, though he continued to be involved in research., ${ }^{9,25} \mathrm{Tu}-$ lane awarded him with an honorary doctorate in 1985 and also the Robert G. Heath Endowed Lectureship and Professorship. ${ }^{9,15}$ At the age of 81 years, just 3 years before his death, Heath published his final major work, Exploring the Mind-Brain Relationship, in which he discussed the highlights of his research at Tulane..$^{12}$ The majority of this work is centered on schizophrenia, which Heath called his "obsession." 15 When asked how he felt about the future of neurology and psychiatry, Heath discussed his optimism for new research and expressed the hope that his work would be used to promote further understanding in both fields. ${ }^{15}$ On September 21, 1999, Dr. Robert G. Heath died at the age of 84 years. ${ }^{3,33}$

Heath authored an estimated 420 articles and 3 books. ${ }^{3}$ Despite having numerous publications, Heath is primarily remembered for the more controversial aspects of his career. The previously described study in which Heath attempted to eliminate a person's homosexuality is often cited today to relay the savage nature of early psychosurgery. It is worth noting that even during its time, those experiments were met with sharp criticism and attention from civil rights organizations. ${ }^{5}$ After his death, a New York Times obituary reiterated some of these criticisms, describing Heath's involvement with CIA-funded academic research and an inability to replicate his taraxein study. ${ }^{33}$ There are others, however, such as The Robert Heath Society, that offer an alternative view of Heath's character. In the article, "Robert G. Heath: 'A Perfect Gentleman," the society's historian explains the historical perspective of Heath and his colleagues and makes a case for Heath as the "perfect gentleman," stating, "Implanting electrodes in the subcortical regions of patients to study the neurochem- 
ical and neurophysiological basis of the brain and behavior required both wisdom and courage." ${ }^{37}$ These contradicting viewpoints illustrate the debated position that Robert Heath holds in media and academia.

Beyond his position as an esteemed faculty member at Tulane, there is no evidence that Heath's successors continued his studies and multidisciplinary research effort. This may be a result of Heath's contentious reputation by the time he retired in 1980. Dr. Daniel K. Winstead is the remaining Robert G. Heath Professor, and, in 2009, Tulane's Department of Neurology and Psychiatry was divided into 2 distinct departments, 60 years after its initial creation. ${ }^{42}$ Similar to Heath's integrated department and controversial studies, the hospital where Heath conducted his research is now obsolete. Declining funds in the 1980s and 1990s caused Charity Hospital to lose accreditation on multiple occasions due to poor conditions. Finally, on August 29, 2005, Hurricane Katrina inundated the hospital along with the city. Patients were evacuated from the hospital by helicopter and boat, which has been reported in sensational detail. Charity Hospital has yet to reopen 12 years after the disaster. ${ }^{2,35}$

\section{Conclusions}

The story of Dr. Robert G. Heath is, at a minimum, an interesting one. Although his research methods and ethical practices are a matter of debate, Heath's belief that the combination of neurochemistry and neurophysiology were responsible for mental illness was progressive for his time. In addition, his early recognition that human behavior was reflected in the brain's electrical activity is laudable. Perhaps one of Heath's lasting contributions is a cautionary reminder of the delicate balance between medical advancements and safe, ethical practices.

\section{References}

1. Agarwal P, Sarris CE, Herschman Y, Agarwal N, Mammis A: Schizophrenia and neurosurgery: a dark past with hope of a brighter future. J Clin Neurosci 34:53-58, 2016

2. Arnon B: Why is New Orleans' Charity Hospital still abandoned 12 years after Hurricane Katrina? Huffington Post. April 17, 2017. (http://www.huffingtonpost.com/entry/ why-is-new-orleans-charity-hospital-still-abandoned us_58f4cba5e4b04cae050dc90e) [Accessed July 12, 2017]

3. Associated Press: Obituary. Robert Galbraith Heath. Associated Press. September 24, 1999

4. Baumeister A: The search for an endogenous schizogen: the strange case of taraxein. J Hist Neurosci 20:106-122, 2011

5. Baumeister AA: The Tulane Electrical Brain Stimulation Program a historical case study in medical ethics. J Hist Neurosci 9:262-278, 2000

6. Becker HC, Founds WL, Peacock SM Jr, Heath RG, Llewellyn RC, Mickle WA: A roentgenographic stereotaxic technique for implanting and maintaining electrodes in the brain of man. Electroencephalogr Clin Neurophysiol 9:533-543, 1957

7. Colvile R: The 'gay cure' experiments that were written out of scientific history. Mosaic Science. July 5, 2016. (https:// mosaicscience.com/story/gay-cure-experiments) [Accessed July 12, 2017]

8. Cotton JM: Sandor Rado 1890-1972. Am J Psychiatry 130:222, 1973

9. Fradelos CK: The Last Desperate Cure: Electrical Brain
Stimulation and Its Controversial Beginnings [dissertation]. Chicago: University of Chicago, 2008

10. Hariz MI: Neurosurgeons were indeed promoting evidencebased, ethical, and multidisciplinary psychiatric surgery! Stereotact Funct Neurosurg 91:270-271, 2013

11. Hariz MI, Blomstedt P, Zrinzo L: Deep brain stimulation between 1947 and 1987: the untold story. Neurosurg Focus 29(2):E1, 2010

12. Heath RG: Exploring the Mind-Brain Relationship. Baton Rouge: Moran Printing, 1996

13. Heath RG: Pleasure and brain activity in man. Deep and surface electroencephalograms during orgasm. J Nerv Ment Dis 154:3-18, 1972

14. Heath RG: Studies in Schizophrenia. A Multidisciplinary Approach to Mind-Brain Relationships. Cambridge, MA: Harvard University Press, 1954

15. Heath RG: Wallace Tomlinson interviewing Robert Heath [video]. New Orleans: Tulane University Rudolph Matas Library, 1987 (https://archive.org/details/ WallaceTomlinsonInterviewingRobertHeath_March51986) [Accessed July 12, 2017]

16. Heath RG, De Balbian Verster F: Effects of chemical stimulation to discrete brain areas. Am J Psychiatry 117:980-990, 1961

17. Heath RG, Guerrero-Figueroa R: Psychotic behavior with evoked septal dysrhythmia: effects of intracerebral acetylcholine and gamma aminobutyric acid. Am J Psychiatry 121:1080-1086, 1965

18. Heath RG, John SB, Fontana CJ: Stereotaxic implantation of electrodes in the human brain: a method for long-term study and treatment. IEEE Trans Biomed Eng 23:296-304, 1976

19. Heath RG, Krupp IM: Catatonia induced in monkeys by antibrain antibody. Am J Psychiatry 123:1499-1504, 1967

20. Heath RG, Leach BE, Byers LW, Martens S, Feigley CA: Pharmacological and biological psychotherapy. Am J Psychiatry 114:683-689, 1958

21. Heath RG, Martens S, Leach BE, Cohen M, Angel C: Effect on behavior in humans with the administration of taraxein. Am J Psychiatry 114:14-24, 1957

22. Heath RG, Martens S, Leach BE, Cohen M, Feigley CA: Behavioral changes in nonpsychotic volunteers following the administration of taraxein, the substance obtained from serum of schizophrenic patients. Am J Psychiatry 114:917920, 1958

23. Heath RG, McCarron KL, O’Neil CE: Antiseptal brain antibody in IgG of schizophrenic patients. Biol Psychiatry 25:725-733, 1989

24. Heath RG, Monroe RR, Mickle WA: Stimulation of the amygdaloid nucleus in a schizophrenic patient. Am J Psychiatry 111:862-863, 1955

25. Heath RG, Sherman SH: The use of drugs in the treatment of traumatic war neuroses. Am J Psychiatry 101:355-360, 1944

26. Mettler FA: Extracortical connections of the primate frontal cerebral cortex; corticifugal connections. J Comp Neurol 86:119-166, 1947

27. Mettler FA: Extracortical connections of the primate frontal cerebral cortex; thalamocortical connections. J Comp Neurol 86:95-117, 1947

28. Moan C, Heath RG: Septal stimulation for the initiation of heterosexual behavior in a homosexual man. J Behav Ther Exp Psychiatry 3:23-30, 1972

29. Mohr CL, Gordon JE: Tulane: the Emergence of a Modern University, 1945-1980. Baton Rouge: Louisiana State University Press, 2001

30. Monroe RR, Heath RG, Mickle WA, Llewellyn RC: Correlation of rhinencephalic electrograms with behavior; a study on humans under the influence of LSD and mescaline. Electroencephalogr Clin Neurophysiol 9:623-642, 1957 
31. Pool JL, Heath RG, Weber JJ: Topectomy; surgical indications and results. Bull N Y Acad Med 25:335-344, 1949

32. Rado S: Graduate residency training in psychoanalytic medicine. Am J Psychiatry 105:111-115, 1948

33. Ravo N: Robert G. Heath, 84, researcher into the causes of schizophrenia. New York Times. September 25, 1999 (http://www.nytimes.com/1999/09/25/us/robert-g-heath84-researcher-into-the-causes-of-schizophrenia.html) [Accessed July 12, 2017]

34. Rushton B: The mysterious experiments of Dr. Robert Heath in which we wonder who is crazy and who is sane. Vieux Carré Courier. August 29, 1974

35. Salvaggio JE: New Orlean's Charity Hospital: A Story of Physicians, Politics and Poverty. Baton Rouge: Louisiana State University Press, 1992

36. Scheflin AW, Opton EM: The Mind Manipulators: A NonFiction Account. New York: Paddington Press, 1978

37. Scrignar CB: Robert G. Heath: "A Perfect Gentleman." Tulane Psychiatry and Neurology Alumni Newsletter 16(1):4, 2005

38. Siegel M, Niswander GD, Sachs E Jr, Stavros D: Taraxein, fact or artifact. Am J Psychiatry 115:819-820, 1959

39. Tomlinson W: Profiles of famous American psychiatrists. Robert G. Heath, M.D. Psychiatr Ann 13:427-428, 1983

40. United States Senate: Quality of Health Care-Human Experimentation, 1973. Hearings Before the Subcommittee on Health of the Committee on Labor and Public Welfare. Washington, DC: US Government Printing Office, 1973
41. Valenstein ES: Brain Control: A Critical Examination of Brain Stimulation and Psychosurgery. New York: Wiley, 1974

42. Winstead DK: Chairman's column. Tulane Psychiatry and Neurology Alumni Newsletter 20(2):1, 2009

\section{Disclosures}

The authors report no conflict of interest concerning the materials or methods used in this study or the findings specified in this paper.

\section{Author Contributions}

Conception and design: Glenn. Acquisition of data: Conner. Drafting the article: O'Neal. Critically revising the article: Baker, Glenn. Reviewed submitted version of manuscript: Sughrue, Conner. Approved the final version of the manuscript on behalf of all authors: Sughrue. Administrative/technical/material support: Sughrue. Study supervision: Sughrue.

\section{Correspondence}

Michael E. Sughrue, Department of Neurosurgery, University of Oklahoma Health Sciences Center, 1000 N Lincoln Blvd., Ste. 4000, Oklahoma City, OK 73104.email: michael-sughrue@ ouhsc.edu. 